\title{
La erección de la Secretaría del Despacho de la Gobernación del Reino para la Península e Islas Adyacentes
}

\author{
The establishment of the Kingdom's \\ Government Office Bureau \\ for the Peninsula and adjacent Islands
}

\author{
Miguel Ángel PÉREZ DE LA CANAL \\ Doctor en Derecho \\ Académico Correspondiente \\ de la Real Academia de Jurisprudencia y Legislación \\ anguelmai@gmail.com
}

Recibido: 13 de enero de 2014

Aceptado: 24 de febrero de 2014

\section{RESUMEN}

Examen de la creación por el artículo 222 de la Constitución de Cádiz de 1812 de la Secretaría del Despacho que indica el título, apuntando las posibles fuentes del mismo. Da cuenta también de una Memoria, que transcribe como apéndice, dirigida a las mismas Cortes por José Señán, en la que propone la creación de esa Secretaría. Termina con una esquemática evolución posterior de la misma.

PALABRAS CLAVE: 1812, Constitución, Secretaría, Gobernación, Señán.

\begin{abstract}
Study of the establishment of the Kingdom's Government Office Bureau by the Article 222 of the 1812 Cadix Constitution, pointing out the possible sources of this Bureau. Included as an appendix is the transcription of a Report signed by José Señán and proposing the creation of the Secretariat. It ends with a schema with the subsequent evolution of the institution.
\end{abstract}

KEYWORDS: 1812, Constitution, Secretariat, Government, Señán.

\section{RÉSUMÉ}

Examen de la création par l'article 222 de la Constitution de Cadix en 1812 du Secrétariat du Bureau du Gouvernement du Royaume pour la Péninsule et les îles adjacentes, soulignant ses possibles sources d'origine. L'article inclut aussi, transcrit en annexe, un rapport dirigé aux Cortes par José Senan, proposant la création du Secrétariat. Un schéma de l'évolution ultérieure de l'institution finit ce travail.

MOTS CLÉ : 1812, Constitution, Secrétariat, Gouvernement, Señán. 
1. El artículo 222 de la Constitución de Cádiz de 19 de marzo de 1812 determina el número y la denominación de los Secretarios del Despacho, y en segundo lugar de los siete que establece menciona por primera vez en la historia de nuestra Administración el Secretario del Despacho de la Gobernación del Reino para la Península e islas adyacentes ${ }^{1}$. El citado precepto había sido examinado por la Comisión de Constitución en sus sesiones de 30 y 31 de julio y 5 de agosto de 1811 ; en la última de las cuales se acordó incluirle en el proyecto de Constitución que estaba preparando con el nombre de Secretaría del Despacho de la Gobernación del Estado². Leído como formando parte del título IV de ese proyecto en la sesión del Pleno de 18 de este último mes $^{3}$, fue aprobada definitivamente la creación de esta Secretaría en la sesión de 14 de diciembre de 1811 con la nueva denominación indicada en el título de este trabajo ${ }^{4}$.

\footnotetext{
${ }^{1}$ Colección de Leyes Fundamentales. Textos editados por Ramón Sáinz de Varanda (Madrid, 1957), 90.

${ }^{2}$ Actas de la Comisión de Constitución (1811-1813). Estudio preliminar por M. ${ }^{\mathrm{a}}$ Cristina Diz-Lois. Coordinador Federico Suárez (Madrid, Instituto de Estudios Políticos, 1976), 153-155 y 160-161. En dicho proyecto figuraban también dos Secretarios del Despacho Universal de Ultramar, uno para los negocios de la América septentrional y las Islas y otro para los de América meridional y las provincias de Asia, y naturalmente los tradicionales de Estado, Gracia y Justicia, Hacienda, Guerra y Marina.
}

${ }^{3}$ Diario de sesiones de las Cortes generales y extraordinarias (en adelante Diario) III (Madrid, 1870), 1.651 .

${ }^{4}$ Diario IV (Madrid, 1870), 2.424-2.425. En la sesión de 22 de octubre de 1811, con anterioridad al inicio del debate sobre la atribución de los asuntos de Ultramar, se había verificado ya un primer examen del artículo 222, en el que se aprobó la creación de esta Secretaría con la denominación de Secretaría del Despacho de la Gobernación del Reino. Antes de tener lugar esa aprobación se mantuvieron dos posiciones distintas, una contraria y otra favorable a la creación de la Secretaría. La primera fue sostenida por los diputados Terrero, Garoz y Borrull, En tanto que el primero de ellos se limitó a manifestar que le parecía demasiado crecido el número de Secretarías propuesto; los otros dos basaron fundamentalmente su oposición en los gastos que habría de ocasionar el nuevo departamento y en que los asuntos de que debía conocer podían seguir siendo despachados por los Secretarios que los habían tenido a su cargo hasta el momento. Por el contrario, en defensa de la nueva de la Secretaría los diputados Polo y Aner alegaron la necesidad y utilidad de su creación, pues al estar reunidos en una sola mano todos las materias que perseguían el fomento y la felicidad de la nación, hasta entonces dispersas por varias Secretarías, habría mayor orden y rapidez en su despacho con general beneficio; y en cuanto a los gastos que la creación llevaría consigo, replicaba el primero de ellos que serían compensados con la disminución de los de las otras Secretarías al quedar privadas de muchas de sus competencias. Por su parte, el diputado Pérez de Castro consideraba el nuevo establecimiento como una consecuencia de la separación de la administración de justicia de la económico-política y gobernativa del Reino establecida por la Constitución (Diario III [n. 3], 2.128-2.130). La nueva denominación fue consecuencia de la creación, en la sesión al principio de esta nota indicada, de la Secretaria del Despacho de la Gobernación del Reino para Ultramar. El primer titular de ella no fue designado hasta el 23 de junio de 1812, en que el Decreto de la Regencia del Reino de esa fecha nombró para ese cargo a José de León y Pizarro, Secretario que había sido del Consejo de Estado (Gaceta de la Regencia de las Españas, número 79, del 27 siguiente, páginas 657-658). 
En las indicadas actuaciones no se ofrece dato alguno que nos permita conocer cuál ha sido la fuente del citado precepto. Se hace preciso por tanto examinar qué organismos precedentes o qué otros factores han podido ser determinantes de la creación del nuevo organismo. En cuanto a lo primero, estimamos que no basta para ser considerado antecedente el mero hecho de desempeñar o haber desempeñado juntamente con otras de diversa naturaleza alguna de las funciones asignadas a la nueva Secretaría, ya que eso nos apartaría del objeto de esa investigación. Debe, por tanto, tratarse de organismos creados específicamente para algunos de los fines atribuidos al nuevo. En este sentido, el origen de la 1a Secretaría del Despacho que estudiamos puede encontrarse en el Departamento del Fomento General del Reino y de la Balanza de Comercio establecido en 1802. Desde el otro punto de vista, también puede estar inspirado en el ejemplo francés, o en el Ministerio de Gobernación del Reino propuesto por la Regencia del Reino en el Plan de nueva organización de los ministerios remitido a la aprobación de las Cortes el 9 de abril de 1811, antes por tanto del 18 de agosto en que como ya hemos visto se leyera en las Cortes la segunda parte del proyecto de Constitución en la que estaba incluido el artículo 222. Aunque no pudo influir propiamente en la creación de la Secretaría del Despacho de la Gobernación del Reino para la Península, habida cuenta de que fue presentada a las Cortes con posterioridad a esa última fecha, creemos necesario hacer referencia, como expresión de un clima reformista a la sazón existente, a la memoria en que se procura demostrar las "Utilidades y ventajas que deben resultar a la Nación española de la creación de un ministerio con el título de Gobernación General del Reino que cuide de la educación pública y de la extensión y fomento de la agricultura, industria, artes y navegación", dirigida a las Cortes el 20 de octubre de 1811 por José Señán y Velázquez.

2. Bajo el influjo de las ideas de la Ilustración, se fueron estableciendo a lo largo del siglo XVIII diversos organismos encaminados a lograr el conocimiento de la verdadera riqueza nacional para adecuar a ella las contribuciones, apartar los obstáculos que se oponían al bienestar de los pueblos y fomentar el progreso de la agricultura, la industria y el comercio. Tales fueron con fines fundamentalmente estadísticos la Secretaría de la Balanza de Comercio, establecida por Real Orden de 18 de abril de 1795, y la Dirección de la Dirección de Fomento, creada 1797 y suprimida a principios de $1798^{5}$. Así las cosas, por Real Orden de 19 de mayo de 1802, dictada siendo Godoy Secretario de Estado y Miguel Cayetano Soler Secretario de Hacienda, se atribuyen a la Secretaría de la Balanza las funciones de la extinguida Dirección del Fomento, dando de esta forma origen al Departamento del Fomento General del Reino y de la Balanza de Comercio, que se adscribe a la Secretaría de Estado y del Despacho

\footnotetext{
${ }^{5}$ Preámbulo de la Real Orden citada en la nota siguiente. Pedro Molas Ribalta, De la Junta de Comercio al Ministerio de Fomento, en Actas del IV Symposium de Historia de la Administración (Madrid, Instituto Nacional de Administración Pública, 1983), 534-543.
} 
Universal de Hacienda ${ }^{6}$. Este organismo, existente al tiempo de la invasión francesa, pudo servir de base a las Cortes para la creación de la nueva Secretaría, agregando a sus funciones estadísticas y de fomento las demás asignadas a esta última. En la antes mencionada Memoria de Señán (capítulos [10] y [13]), se reconoce que las principales atribuciones señaladas al nuevo Ministerio son las mismas que las del Departamento, el cual, como se dice en el segundo de los capítulos citados, "debe refundirse en el, aunque con extensión a otros objetos que este no abrazaba, pero que por su estrecha conexión y enlace deben caminar unidos". De igual modo, en el Real Decreto de 5 de noviembre de 1832, que más delante mencionamos, se considera al Departamento como un precedente de la Secretaría que establece.

3. El ejemplo en general de la legislación francesa en la elaboración de nuestra Constitución de 1812 es un hecho generalmente admitido ${ }^{7}$. En el caso concreto de la creación de la Secretaría de la Gobernación del Reino para la Península e Islas adyacentes, pudo imitarse el Ministerio del Interior creado por la Ley de 27 de abril-25 de mayo de 1791, que pasó a formar el artículo LVIII de la Constitución acordada por la Asamblea legislativa ese mismo año ${ }^{8}$ y que sin duda fue tenido en cuenta al extender el artículo 27 de la Constitución otorgada por el rey José Bonaparte en Bayona el 6 de julio de $1808^{9}$. Este influjo debió de llegar a las Cortes de Cádiz a través del Consejero de Hacienda, Antonio Ranz Romanillos ${ }^{10}$, que en virtud de nombramiento del Emperador había actuado de Secretario en la Asamblea de Bayona, y juntamente con los demás asistentes a ella prestó a la Constitución allí aprobada su asentimiento y aceptación, según el acta extendida en Bayona el 7 de julio de $1808^{11}$.

\footnotetext{
${ }^{6}$ Reglamento del Departamento del Fomento General del Reino y de la Balanza de Comercio. Madrid en la Imprenta Real. Año de 1802. Hay un ejemplar en el Archivo Histórico Nacional, Diversos, Reales Cédulas, número 1.428. José Canga Argüelles, Diccionario de Hacienda con aplicación a España I (Madrid, 1833), 116-119. Molas, De la Junta (n. 5), 543-546.

${ }^{7}$ Ismael Sánchez Bella, La polémica sobre las fuentes de la Constitución española de 1808, en IV Congreso Internacional de Historia de América V (Buenos Aires, 1966), 673-687. La influencia francesa fue ya señalada por Fernando VII cuando en el Real Decreto dado en Valencia el 4 de mayo de 1814 afirma que en la Constitución de 1812 se copiaron los principios revolucionarios y democráticos de la Constitución francesa de 1791 (Decretos del Rey Don Fernando VII I [Madrid, en la Imprenta Real, 1818] 1-9). Concretamente, la relación entre la relación entre la Secretaría de la Gobernación del Reino y el Ministerio del Interior francés fue ya apuntada por el diputado Borrull en la discusión del proyecto constitucional (n. 4).

${ }^{8}$ M. Faustin-Adolpe Hélie, Les constitutions de la France (Paris, 1875), 219-221. La Constitución francesa de 1791 no es otra cosa que una ordenada recopilación de actos precedentemente adoptados por la Asamblea Nacional (L. Dupriez, Les ministres dans les principaux pays d'Europe el d'Amerique II (Paris, 1893), 268.

${ }^{9}$ Carlos Sanz Cid, La Constitución de Bayona (Madrid, 1922), 423.

${ }^{10} \mathrm{M}^{\mathrm{a}}$ Cristina Diz-Lois, Estudio preliminar, en Actas (n. 2), 30-40. Raúl Morodo, Bayona y Cádiz desde Filadelfia. Notas sobre Carlos Le Brun, en José Antonio Escudero (Dir), Cortes y Constitución de Cádiz 200 años I (Madrid, Espasa, 2011), 44-45 hace un breve retrato de Ranz Romanillos.

${ }^{11}$ Sanz, La Constitución (n. 9), 117 y 440-442. Según Le Brun, citado por Diz-Lois en la página 34 del trabajo mencionado en la nota siguiente, Ranz "en la época napoleónica extendió en Bayona la Cons-
} 
Anteriormente, había sido el principal inspirador de los trabajos realizados por la Junta de Legislación existente en la Comisión de Cortes creada por Decreto de la Junta Central de 8 de junio de $1808^{12}$, y el autor en vista de ellos de un proyecto de constitución que le fue solicitado por la Comisión nombrada por las Cortes para elaborar otro proyecto de texto constituciona $1^{13}$, de la cual Ranz Romanillos formaba parte como mero invitado ${ }^{14}$, lo que no le impidió desempeñar en ella una muy importante labor ${ }^{15}$.

4. El Plan de nueva organización de los ministerios del Consejo de Regencia tiene su origen en el "Ensayo sobre la clasificación de los ministerios del despacho y otros puntos análogos a su organización y a la de las secretarías", presentado el 28 de septiembre de 1810 por Eusebio de Bardagí y Azara, y primer Secretario de Estado y del Despacho, a la Regencia del Reino, la cual tuvo a bien oir en varias sesiones a los demás Secretarios del Despacho; efectuado esto, dispuso que cada uno de ellos expusiera su dictamen por escrito, y después emitidos estos y leídos ante el Consejo de Regencia con las observaciones que cada uno tuvo por conveniente hacer, expuso este su parecer en términos que Bardagí comunicó a los Secretarios diputados en oficio de 9 de abril de 1811, al que acompañaban el "Ensayo" y los dictámenes de los demás Secretarios ${ }^{16}$.

Llegado ese escrito a las Cortes, acuerdan estas el siguiente día 10 que examine el asunto una Comisión, formada en la del 14 con los diputados Pérez de Castro, Utgés, Parada, Navarro y Argüelles, la cual emite el 20 del mismo mes un dictamen, en el que propone a los representantes de la Nación que se apruebe en todas sus partes el pensamiento del Consejo de Regencia expuesto en el antes citado oficio de Bardagí; ese mismo día se lee en las Cortes todo el material remitido por este último, y con-

titución, y el Emperador le regaló una caja de oro con su retrato por este servicio". Por su parte, Ángel Salcedo Ruiz (Historia de España. Resumen crítico [Madrid, 1914], 447) afirma que en Bayona "fue presentado el proyecto de Constitución, obra de un de monsieur Sménard, francés domiciliado largo tiempo en España, que lo remitió a Napoleón en septiembre de 1807; el Emperador lo tuvo en cartera hasta este tiempo, que lo revisaron Azanza y Urquijo y en diez sesiones fue aprobado".

${ }^{12}$ Diz Lois, Estudio (n. 2), 40-51; y también Federico Suárez, El proceso de convocatoria de Cortes (1808-1810) (Pamplona, EUNSA, 1982), pássim, especialmente 260-268, y Francisco Tomás y Valiente, "Génesis de la Constitución de 1812. I. De muchas Leyes fundamentales a una nueva Constitución", Anuario de Historia del Derecho Español (en adelante AHDE) 65 (1995), 56-102).

${ }^{13}$ Sesión de 6 de marzo de 1811 (Actas [n. 2]), 73). La Comisión de Constitución fue designada por el Presidente de las Cortes, y se dio cuenta de ella en la sesión de 23 de diciembre de 1810 (Diario II [Madrid, 1870], 55).

${ }^{14}$ Sesión de 12 de marzo de 1811 (Actas [n. 2], 74-75). En la del anterior día 2, primera de las celebradas, se acordó que "se convidaría por la Comisión a algunos sujetos instruidos que designará de fuera de ella y de las Cortes, que asistiesen a sus conferencias para ilustrar con su conocimientos (ibid., 72-73). Solo Ranz fue convidado.

${ }^{15}$ En las Actas (n. 2) consta su intervención en 21 sesiones (páginas 80, 81, 84, 111, 120, 123, 179, 180, 186-188, 191-193, 198, 199, 207, 209, 210, 228, 230 у 231).

${ }^{16}$ Inserto en el impreso citado en la nota siguiente. 
cluida la lectura se manifiestan en ellas dos posiciones contrapuestas, pues mientras que de un lado los disputados Esteban, Traver y Ricardo estiman, el primero que el asunto es de mucha importancia y debe procederse con atención, y los otros dos que es incluso constitucional, otros diputados entienden que se trata de un mero arreglo de ministerios (Pérez de Castro y Aner), que carece de importancia (Muñoz Torrero, Presidente pro tempore de las Cortes), y que no afecta a la Constitución (Argüelles); en esta misma sesión se acuerda imprimir el Plan y el dictamen de la Comisión, y en la del día siguiente la de todo el material ${ }^{17}$.

El "Ensayo" de Bardagí constituye un intento de redistribución de competencias administrativas, separando de cada una de las Secretarías del Despacho el conocimiento de aquellos asuntos que no pertenecieran a su peculiar cometido, para pasarlos al de aquella otra en la que encajarán más propiamente por razón de sus privativas atribuciones, o a la de la Gobernación del Reino de nueva creación los que no fueran propios de las existentes; o también a los tribunales, si a ellos pertenecieran.

En lo que se refiere a las atribuciones de la nueva Secretaría, el "Ensayo" le atribuye en general cuanto es relativo a la Administración civil del reino y a la policía municipal de todos los pueblos sin excepción, es decir incluidos los sitios reales, y en particular según sus propios términos las siguientes, análogos todos ellos a los de su homónimo francés:

a) La salubridad y el buen orden en los abastecimientos y mercados.

b) La limpieza de las poblaciones y su embellecimiento.

c) La seguridad pública en los pueblos, ciudades y caminos.

d) El orden y dirección en los teatros y demás diversiones públicas.

e) Todo lo que es relativo al aseo, decencia, seguridad, orden y sosiego interior del Estado.

f) El cuidado en descubrir las tramas de los malintencionados, y de observar y comprimir todo manejo, conventículo o inconsiderada propalación dirigida a perjudicar el sosiego interior o seguridad pública y el examen de la conducta de las gentes sin ocupación, mal entretenidas o sospechosas.

g) Lo relativo a la instrucción o enseñanza pública, como colegios, universidades, academias, escuelas elementales y establecimientos de ciencia y bellas artes, con cuanto pertenezca a estos interesantes ramos de la ilustración nacional.

h) Los caminos, canales acequias, desecaciones de lagunas o pantanos, y toda obra pública rural o urbana de cualquier especie, sea de utilidad o de entretenimiento $\mathrm{u}$ ornato.

\footnotetext{
${ }^{17}$ Diario II (n. 13), 856, 865, 900, 907. La impresión se hace en Cádiz, en la Imprenta Real, sin indicación de año, en un folleto en cuarto menor de 51 páginas, del que existe un ejemplar en la Biblioteca de la Real Academia de Jurisprudencia y Legislación. Lo hemos reproducido en Un plan de nueva organización de los ministerios, formado por el Consejo de Regencia en 1811, en Documentación Administrativa, 194 (abril-junio 1982), 213-267.
} 
i) La sanidad.

j) Las fábricas y demás ramos de la industria nacional en aquella parte que el Gobierno deba tomar en su fomento y prosperidad.

k) Los adelantamientos de la agricultura y de los establecimientos públicos de ella.

1) Las minas y canteras.

m) Las casas de monta.

n) Las crías de ganados.

o) La navegación y comercio interior.

p) Los hospitales civiles.

q) Lazaretos.

r) Las casas y establecimientos de misericordia y beneficencia.

s) Los asuntos de las encomiendas de los infantes.

t) La imprenta real.

u) Cuanto se refiera a la fijación de límites de las provincias y pueblos.

v) La estadística y la economía política en general.

w) Los asuntos pertenecientes al interior del reino desempeñados por los otros ministerios.

Por su parte, el Consejo de Regencia en su Plan no incluye entre las atribuciones del nuevo ministerio las señaladas anteriormente con las letras c), e) y f), relativas todas ellas a las funciones de policía; las casas de monta (letra $\mathrm{m}$ ), los lazaretos (letra q), los asuntos de las encomiendas de los infantes (letra s), la imprenta real (letra s) y la cláusula general expresada al final de la enumeración. Por lo que se refiere a la policía, tras afirmar que en España jamás se ha conocido lo que es policía liberal, y que cuantas veces se ha querido introducirla otras tantas ha sido necesario suprimirla por las vejaciones que ocasionaba, reconoce que es preciso establecer urgentemente una policía vigilante que descubra las tramas del enemigo y esté siempre alerta para evitar que se introduzcan espías entre nosotros. No obstante, vacila entre la atribución de la policía a la nueva Secretaría o la creación una superintendencia general que se ocupe expresamente de ella, y ante la duda prefiere esperar a que concluyan los trabajos que sobre ese asunto ha mandado realizar, y entonces los presentará a las Cortes para que estas determinen lo que estimen más conveniente.

Hasta el 8 de noviembre de 1811 las Cortes no vuelven a ocuparse del Plan de la Regencia. En la sesión de ese día. se leyó el dictamen de la Comisión nombrada para informar sobre el Plan y en la del siguiente 11 acordaron encomendar a aquella las atribuciones que en el mismo se indicaban, añadiendo, además, el ramo de policía, que la Regencia no le había decidido a asignarle ${ }^{18}$. Llegados a este punto, advierten sin duda las Cortes que el Plan de la Regencia parte de la existencia de un número y denominación de ministerios sobre lo cual ellas mismas no han pronunciado aún la

${ }^{18}$ Diario III (n. 3), 2.229 y 2.248. 
última palabra, y de ahí que en la sesión de 12 de noviembre de 1811 acuerden suspender la discusión del arreglo ministerial, y que la Comisión que ha entendido del mismo formule un nuevo dictamen en vista de las futuras resoluciones de las Cortes sobre el proyecto de Constitución ${ }^{19}$.

Este nuevo dictamen lo presenta la que se denomina ahora Comisión encargada del despacho del expediente sobre arreglo de las Secretarías del Despacho en la sesión del 7 de marzo de 1812; y en lo que se refiere a la de la Gobernación de la Península, estima conveniente agregarle el ramo de correos, por la relación que guarda con la materia de vías de comunicación perteneciente a la misma, así como la renta correos, para atender a los gastos que ocasiona la correspondencia; opina por último que la Secretaría de la Estampilla debe quedar bajo la dependencia de esta Secretaría de Gobernación; y en consecuencia de esas apreciaciones, y de las que hace sobre las atribuciones de los demás ministerios, propone a las Cortes un borrador de Decreto sobre los negocios que corresponden a las Secretarías del Despacho ${ }^{20}$. Discutido el borrador en las sesiones de 22, 23, 24, 25 y 28 de marzo, en la primera de las cuales se modifica aquel levemente el artículo de de la Secretaría de Gobernación en lo tocante al ramo y renta de correos y postas y a la Secretaría de la Estampilla ${ }^{21}$, se promulga al fin el Decreto con el número CXLV el 6 de abril de 1812, en cuyo artículo segundo se fijan las atribuciones de nuestra Secretaría en los siguientes términos, coincidentes en su casi totalidad con los del "Ensayo" del Secretario Bardají:

La Secretaría del Despacho de la Gobernación del Reino para la Península entenderá en todo lo perteneciente al gobierno político y económico del Reino, como es la policía municipal de todos los pueblos sin distinción, entendiéndose por ella la salubridad de los abastecimientos y mercados, limpieza y adorno de las poblaciones: en todo lo respectivo a la instrucción pública, como escuelas, colegios, universidades, academias y demás establecimientos de ciencias y bellas artes, conforme al plan y reglamento que establezcan las Cortes: en lo correspondiente a caminos, canales, puentes, acequias, disecaciones de lagunas y pantanos, y toda obra pública de utilidad u ornato: en el ramo de sanidad: en todo lo que por las leyes pueda tocar al Gobierno para promover y fomentar la agricultura e industria nacional en todos sus ramos, y en los establecimientos públicos de ambas. Tendrá a su cuidado las minas y canteras de todas clases que pertenezcan al Estado: la navegación y comercio del interior: los hospitales, cárceles, casas de misericordia y de beneficencia: la fijación de límites de las provincias y pueblos, y todo lo correspondiente a la estadística y economía política: el ramo general de correos y postas en toda la Monarquía: la estampilla del Rey y del Presidente de la Regencia (quedando por ahora la Secretaría de la misma estampilla en la forma que actualmente tiene), y la provisión de todos los empleos que sean correspondientes a todos los ramos que comprende este Ministro (sic) ${ }^{22}$.

\footnotetext{
${ }^{19}$ Diario III (n. 3 ), 2.252.

${ }^{20}$ Diario IV (n. 4). 2.383-2.385.

${ }^{21}$ Diario IV (n. anterior), 2.965, 2.969, 2.972, 2.975 у 2.980.

${ }^{22}$ Colección de los Decretos y Ordenes que han expedido las Cortes generales y extraordinarias desde el 24 de septiembre de 1811 hasta el 24 de mayo de 1812 II (Sevilla, Imprenta Mayor de la Ciudad, 1820), 177-182.
} 
5. Como antes hemos dicho, la Memoria de Señán fue dirigida a los Secretarios de las Cortes con oficio de 20 de octubre de 1811. El día siguiente, acuerda la Mesa de Estado que "pase a la Comisión de Constitución para que la tenga presente y produzca los efectos a que haya lugar"; y de ella no volvemos a encontrar más datos hasta que el 12 de octubre de 1813 se acuerda el archivo de la misma ${ }^{23}$.

Nacido en Segovia el 15 de diciembre de $1768^{24}$, era Señán un relevante empleado de la Secretaría del Despacho de Hacienda, en la que prestó servicios en Madrid, Sevilla y Cádiz, la mayor parte de ellos como Oficial de la Secretaría de la Balanza de Comercio y del Departamento del Fomento General del Reino y de la Balanza de Comercio, por espacio de 34 años, 9 meses y 3 días, según resulta de la certificación expedida en Madrid el 30 de junio de 1828 por el Comisionado de Real Orden para la clasificación de sueldos a los jubilados y cesantes de los Ministerios de Estado, de Gracia y Justicia y de Hacienda. El 27 de mayo de 1808, el Duque de Berg, de acuerdo con la Junta Suprema de Gobierno, le designó para asistir a la Asamblea que había de celebrarse en Bayona, pero iniciado el viaje con el Consejo Real se separó en Sepúlveda de la comitiva pretextando una enfermedad de pecho, y se trasladó de incógnito a Segovia, donde permaneció hasta que pudo regresar a la Corte una vez que las tropas francesas abandonaron Madrid después de la batalla de Bailén. Su carrera administrativa sufrió las vicisitudes del régimen constitucional.

De su preparación, laboriosidad y celo son ejemplo la traducción de los aranceles franceses y la de un proyecto de ley sobre las aduanas de Francia, trabajos por los que se le manifestó el Real aprecio, y la corrección de pruebas de los aranceles de Inglaterra. En virtud de privilegios reales de 3 de diciembre de 1800, 3 de junio de 1804 y 13 de febrero de 1816 publicó la Guía o Estado General de la Real Hacienda de España por sendos periodos de cuatro años. También se le concedió un privilegio exclusivo para publicar la Instrucción General de Rentas de 16 de abril de 1816. Apartado ya del servicio activo, el 12 de julio de 1824 envió al Director General de la Deuda del Estado unas observaciones para facilitar la verdadera inteligencia y el oportuno conocimiento de los expedientes concernientes a esa materia.

La Memoria de Señán trata parcialmente del mismo tema que el Plan de la Regencia, pero lo enfoca desde un ángulo diferente, pues así como para este último el establecimiento de la Secretaría de la Gobernación del Reino para la Península constituye un mero intento global de redistribución de competencias administrativas entre las Secretarías del Despacho, para Señán la creación del nuevo organismo tiene una

\footnotetext{
${ }^{23}$ Se conserva en el Archivo del Congreso de los Diputados, Serie General de Expedientes, legajo 7, número 20. Dado su indudable interés, la incluimos como apéndice del presente trabajo. En la transcripción hemos adaptado su texto a las normas lingüísticas actuales en los muy contados casos en que lo consideramos indicado. También hemos numerado los párrafos, y dado numeración seguida a las notas, que en el original figuran independientes por páginas.

${ }^{24}$ Este dato y los demás que a continuación indicamos constan en su expediente personal, conservado en el Archivo Histórico Nacional, Fondos Contemporáneos, Ministerio de Hacienda, legajo 1.501.
} 
finalidad esencialmente política, como lo es la de potenciar las fuentes de la riqueza nacional en beneficio tanto de los particulares como del Estado, por la interdependencia existente entre ambos. Por eso después de denunciar el estado de abatimiento en que se encontraban en España la agriculturas, la industria y el comercio y de poner de relieve los defectos de la Administración pública considera necesaria la introducción de medidas que reformen ese estado de cosas, y entre ellas de modo especial la creación de una Secretaría que concentre en sus manos el manejo todos los ramos que contribuyen a la felicidad de la Monarquía (párrafos [1] al [9]).

Manifiesta que para cumplir ese importante objeto se había creado en 1802 el a la sazón todavía existente Departamento del Fomento General del Reino y de la Balanza de Comercio, dependiente de la Secretaría del Despacho de Hacienda, que estaba entonces a cargo de Bartolomé Soler, pero que había sucumbido, aunque fueron importantes los trabajos en parte publicados que llevó a cabo, por los inconvenientes, dificultades y trabas que se pusieron a su funcionamiento, entre ellas la deficiencia de los datos sobre la riqueza de los particulares remitidos por los Intendentes, debidas la falsedad de las declaraciones de productos agrícolas, industriales y comerciales hechas por aquellos ante el temor de que sirvieran para crear nuevas contribuciones o elevar las existentes, de tal modo que para formar la estadística de la provincia de Ávila se vio obligado el Departamento a enviar a uno de sus oficiales para que recorriéndola personalmente pudiese rectificar sobre el terreno los datos y noticias que se habían facilitado de la misma, en cuya labor empleó dos años; y también por la falta de apoyo y protección que a poco de su establecimiento le prestaron las autoridades de que dependía y la oposición de quienes recelaban perder las atribuciones de que habían asumido hasta entonces, y asimismo por el estado de guerra marítima con Inglaterra en que por entonces nos encontrábamos (párrafos [11] y [12]). Ante esta situación, se muestra de acuerdo con el establecimiento de la nueva Secretaría (párrafo [10]), pues al no depender de ninguna otra autoridad podrán así remediarse todos aquellos inconvenientes, con gran utilidad general y sin ello traiga consigo el incremento de los gastos del Estado, pues pueden aplicarse a su sostenimiento todos los arbitrios ya establecidos a favor del Departamento (párrafo [13]). De igual modo, le parece acertada la designación de sus atribuciones, de la únicamente se aparta en lo concernientes al ramo de policía, que a su juicio debe seguir en la Secretaría de Justicia (párrafo [14], nota [5]), y destaca que nada se dice de los censos de población, que entiende deben ser de cargo de esta Secretaría de la Gobernación (párrafo [14], nota [9]).

6. No le fue fácil a la nueva Secretaría incardinarse en el esquema administrativo. Reintegrado Fernando VII en el ejercicio de su poder absoluto a comienzos de 1814, la mantuvo de momento sobre el papel, no obstante el Real Decreto dado en Valencia el 4 de mayo de dicho año, que declaró nulos y de ningún valor ni efecto la Constitución de 1812 y los decretos de las Cortes generales y extraordinarias y las ordinarias a la sazón abiertas en cuanto fueran depresivos de los derechos y prerrogativas de su 
Real soberanía ${ }^{25}$; y aunque no se designó titular de ella en otro Real Decreto de nombramiento de Secretarios de Estado y del Despacho de la misma fecha, sí le fue señalado día y hora para el despacho ${ }^{26}$. Así continuó hasta que fue suprimida por el Real Decreto de 19 de julio de aquel año ${ }^{27}$, consecuencia de otro del mismo día en el que se dispuso que por las Secretarías de Estado y del Despacho corrieran los mismos asuntos que despachaban en 1808, salvo los del Ministerio Universal de Indias ${ }^{28}$, que el Real Decreto de 28 del precedente mes junio, al mismo tiempo que suprimía la Secretaría de la Gobernación de Ultramar, acababa de restablecer como estaba hasta el 8 de julio de $1787^{29}$. En su compleja evolución posterior, la Secretaría es restablecida en $1820^{30}$; en 1823 cambia su denominación por la de Ministerio de lo Interior ${ }^{31}$ y es de nuevo suprimida ese mismo año ${ }^{32}$; y tras un fallido intento en $1830^{33}$ vuelve a ser creada en 1832 con el nombre de Secretaría de Estado y del Despacho del Fomento General del Reino ${ }^{34}$; se la denomina de nuevo del Interior en $1834^{35}$, y de Gobernación del Reino en $1835^{36}$; queda privada de titular en $1923^{37}$, lo recobra en $1925^{38}$; des-

\footnotetext{
${ }^{25}$ Decretos del Rey nuestro Señor Don Fernando VII. Año primero de su restitución al Trono de las Españas I (Madrid, Imprenta Real, 1818), 1-9.

${ }^{26}$ Decretos (n. anterior), 10-11.

${ }^{27}$ Decretos (n. 25), 132.

${ }^{28}$ Decretos (n. 25), 127

${ }^{29}$ Decretos (n. 25), 102. Un Real Decreto dictado en esa fecha había creado dos Secretarías de Estado y del Despacho de Indias, una de Gracia y Justicia y materias eclesiásticas, y otra de Guerra, Hacienda, Comercio y Navegación, en lugar de la única que para el exclusivo despacho de dichos negocios existía entonces (José Antonio Escudero, Los orígenes del Consejo de Ministros en España I (Madrid, Editora Nacional, 1979), 444-445.

${ }^{30}$ Real Decreto de 10 de marzo de 1820 (Gaceta extraordinaria de Madrid del 12).-Miguel Ángel Pérez de la Canal, Restablecimiento de la gobernación constitucional del interior de Reino en 1820, en AHDE (n. 12), 61 (1991), 557-558.

${ }^{31}$ Real Decreto de 27 de mayo (Decretos y Resoluciones de la Junta provisional, Regencia del Reino y las expedidas por Su Majestad desde que fue libre del tiránico poder revolucionario 7 (Madrid, Imprenta Real, 1824), 8-9.

${ }^{32}$ Real Decreto de 18 de octubre (Decretos [n. anterior], 166-67).

${ }^{33}$ Sesión del Consejo de Ministros de 6 de noviembre (Actas del Consejo de Ministros. Fernando VII, V (1830) [Madrid, Ministerio de Relaciones con las Cortes y de la Secretaría del Gobierno, 1992), 291292. De este intento se hace mención en el preámbulo del Real Decreto citado en la nota siguiente.

${ }^{34}$ Real Decreto de 5 de noviembre (Decretos del Rey nuestro Señor Don Fernando VII, y de la Reina su augusta Esposa: Reales órdenes, resoluciones y reglamentos generales expedidos por las Secretarías del Despacho universal y Consejos de S.M. 17 (Madrid, Imprenta Real, 1833), 237-238. Federico Suárez, "La creación del Ministerio del Interior en España", $A H D E$ (n. 12) 19 (1948-1949), 15-56.

${ }^{35}$ Real Decreto de 13 de mayo (Decretos de la Reina nuestra Señora Doña Isabel II, dados sen su Real nombre por su augusta Madre la Reina gobernadora, y Reales órdenes, resoluciones y reglamentos generales expedidos por las Secretarías del Despacho universal 19 (Madrid, Imprenta Real, 1835), 260-261.

${ }^{36}$ Real Decreto de 4 de diciembre (Decretos [n. anterior] 20, 555).

${ }^{37}$ Gaceta de Madrid del 16.

${ }^{38}$ Real Decreto de 3 de diciembre (Gaceta [n. anterior] del 4.
} 
aparece de la organización administrativa en $1936^{39}$; aparece otra vez en ella en 1938 con el nombre de Ministerio del Interior ${ }^{40}$, cambiado a fines de ese mismo año por el de Ministerio de la Gobernación ${ }^{41}$ que mantiene hasta 1977, en el que recibe por cuarta vez, y lo conserva hasta nuestros días, el de Ministerio del Interior ${ }^{42}$.

\footnotetext{
${ }^{39}$ Decreto de la Presidencia de la Junta de Defensa Nacional de 24 de julio (Boletín Oficial de la Junta de Defensa Nacional de España del 25) y Ley de 1 de octubre (Boletín Oficial del Estado, en adelante $B O E$, del 3). Esta última crea un Gobernador General. Miguel Ángel Pérez de la Canal, La Junta de Defensa Nacional de España (24 de julio a 29 de septiembre de 1936), en Homenaje al profesor José Antonio Escudero III (Madrid, Editorial Complutense, 2012), 495-520, y La reestructuración administrativa del Movimiento Nacional establecida en 1 de octubre de 1936 (en curso de publicación).

${ }^{40}$ Ley de 30 de enero (BOE del 31).

${ }^{41}$ Ley de 29 de diciembre (BOE del 31).

${ }^{42}$ Real Decreto de 4 de julio de 1977 ( $B O E$ del 5).
} 


\section{APÉNDICE}

Utilidades y ventajas que deben resultar a la Nación española de la erección de un Ministerio con el título de Gobernación General del Reino que cuide de la educación pública y de la extensión y fomento de su agricultura, industria, artes, comercio y navegación.

Archivo del Congreso de los Diputados, Serie General de Expedientes, legajo 7, no 20.

[1] Si la riqueza de un Estado está siempre en razón de la de los particulares que le componen, deberá ser el primer cuidado de un Gobierno sabio y sólidamente constituido promover la felicidad y bienestar de sus súbditos; y como todos los capitales, o sean fondos, de estos mismos individuos han de traer necesariamente su origen de las utilidades que les produzca su privativa agricultura, industria y tráfico, es claro que estos objetos deben ser los que estén más protegidos por el Gobierno mismo a quien tanto interés le acarrean como único medio de adquirir y conservar su dignidad y un lugar distinguido en el orden de las Naciones grandes.

[2] La naturaleza de este papel no permite dar demasiada extensión a las reflexiones que sobre tan importantes materias se ofrecen a mi imaginación, y habré de limitarme a sólo dar idea de los principios generales que el Gobierno español debe adoptar si, como es de esperar, desea llegar algún día al alto grado de poderío de que es capaz.

[3] Digo capaz porque si examinamos la situación topográfica de España, su clima, la naturaleza y feracidad de su suelo, la excelencia de sus frutos, la calidad y abundancia de sus primeras materias, sus proporciones para el tráfico interior y de puerto a puerto, su dilatada costa marítima, sus muchos y cómodos puertos y ensenadas, sus vastas posesiones ultramarinas, cuyos frutos son preciosos y sus minas de oro y plata cuantiosas y abundantes, se deducirá que no hay Nación alguna que deba aventajarla en los medios de hacer con utilidad general de sus individuos y particular de los fondos del Estado un comercio más activo y ventajoso, dando salida por medio de él a los productos de su suelo y a las manufacturas y artefactos de sus fábricas y talleres.

[4] Partiendo, pues, del principio que dejo establecido se saca la consecuencia de que la sabiduría de todo Gobierno debe consistir en conservar a sus súbditos en el goce de una paz estable en cuanto lo permita el decoro de la Nación que represente, cuidar de la observancia de las leyes que la gobiernen, proteger al vasallo y garantirle su seguridad personal y la de sus propiedades, vejarle lo menos que sea posible con contribuciones pesadas y onerosas, facilitarle los medios de que pueda emplear con utilidad propia y del Estado sus fondos, conocimientos y luces en cualesquiera de los ramos que contribuyen a la felicidad de una Monarquía moderada y constitucional; y finalmente conservar las ventajas que goce sobre otras Naciones con quienes mantenga relaciones políticas y mercantiles, afianzando el disfrute de las ya obtenidas y procurando conseguir otras sobre las demás con quienes no las tenga entabladas, haciendo a este fin los tratados y convenios que le parezcan oportunos al objeto. Este sistema, al paso que aumentará la riqueza territorial, industrial y comercial, y por consiguiente la del Estado, promoverá la población y mejorará la suerte de los ciudadanos, disminuyendo proporcionalmente el ocio, origen de todos los vicios.

[5] Dedicados los hombres de algún tiempo a esta parte al estudio de las ciencias naturales y exactas, al de la economía política, y a entrar en meditaciones profundas sobre los intereses 
de las diversas Naciones de la tierra, no han podido menos de convenir por fruto de todas ellas en la necesidad que tienen las que se hallan en el caso de poder ser agricultoras, artistas y comerciantes de averiguar cuáles son los diversos productos de sus tierras, clasificando antes sus distintas calidades; cuáles las primeras materias y manufacturas de sus fábricas; de qué entidad son los trabajos de sus talleres, y de qué importancia puede ser su comercio interior y exterior, con distinción de lo necesario para consumo propio y mantener su tráfico de prov[inci]a a provincia y de puerto a puerto con utilidad conocida de la marina mercante nacional o costera; qué trabas sufren estos ramos de riqueza y prosperidad nacional y de qué medios debe valerse un Gobierno sabio para hacerlas desaparecer; qué influjo tienen en su decadencia las contribuciones reales y las municipales de los pueblos: qué proporción guardan estas con la población y riqueza territorial, industrial y comercial del país en que están establecidas, y cuál puede ser el sistema de impuestos que menos perjuicios cause a su extensión y fomento. Finalmente, qué artículos por sobrantes o superfluos pueden exportarse al extranjero y a las colonias o posesiones ultramarinas, ya cambiándolos por otros de que carezca la Metrópoli, y ya vendiéndolos a dinero e importando su valor o el producto de sus minas. Desgraciadamente, la España se encuentra de muchos años a esta parte en el fatal estado de hacer un comercio muy pasivo, particularmente desde el descubrimiento del Nuevo Mundo y de las ricas y abundantes minas de oro y plata que se encuentran en aquellos Dominios. Esta copia de metales preciosos llamó desde aquella época la codicia de los españoles, excitó en ellos la emigración y despoblación de la Península, paralizó la industria nacional, coartó la agricultura y constituyó a una gran parte de sus habitantes en el ocio y los placeres, resultando de todo que no alcanzando los productos de la tierra ni los de las fábricas nacionales para surtir el suelo español, ni proveer a las necesidades de los habitantes de la América de los objetos precisos para cubrir sus necesidades, ni satisfacer su lujo y sus caprichos, se ve obligada a suplir su falta con los productos de la industria extraña, que saca en cambio todo el oro y plata que producen las minas de aquellas regiones, viniendo a ser España una mera aduana de tránsito o un canal por donde son conducidos a otros países aquellos preciosos metales.

[6] El estado de la agricultura, industria, artes, comercio y navegación de España no era el más halagüeño antes de su actual revolución, pero el en que quedará después de terminada la presente guerra será sin comparación más lastimoso y sensible por el sistema destructor con que la ejecutan los enemigos de nuestro reposo. Por lo tanto, cuando estos se alejen de nuestro suelo habrá necesidad de aplicar unos remedios prontos, activos y eficaces para reparar el grave daño que habrá causado en estos ramos de prosperidad nacional; y yo entiendo que debemos vivir prevenidos para entonces, empezando desde luego a establecer con solidez las bases sobre que deberá colocarse el nuevo edificio que se trata de construir.

[7] Tiempo es ya de que salgamos del letargo y adormecimiento en que hemos subsistido tantos años, y que consultando los verdaderos intereses de la Nación española la elevemos por medio de sabias instituciones al grado de poderío y grandeza de que es susceptible.

[8] Este grande objeto se conseguirá por medio de una sabia Constitución ${ }^{(1)}$; con una educación ilustrada, formando a este efecto un plan de enseñanza y de estudios cual conviene es-

(1) Tenía ya escrita esta Memoria cuando ocurrió la lectura en el Congreso nacional de la parte ordenada de la Constitución española en cuanto tiene relación con los ramos legislativo y ejecutivo. El concurso de todas clases fue numeroso, y con su profundo y majestuoso silencio dio señales nada equívocas de la aprobación que le merecía. El orden, método, claridad y tino con que está tratada materia tan impor- 
tablecer en las actuales circunstancias ${ }^{(2)}$; con una indagación escrupulosa del estado de la agricultura, industria, artes, comercio y navegación nacional; medios de remover los obstáculos que se oponen a la extensión, propagación y fomento de estos ramos de felicidad pública, y a la de otros muchos que les son análogos y tienen entre sí tal enlace y conexión que no deben manejarse con separación, sino partir de un solo punto que sirva como de centro de unidad de donde emanen todas las providencias que se dirijan a poner en movimiento y rotación las partes todas de la gran máquina del Estado, de esta máquina cuya construcción debe ser perfecta y su movimiento igual y sostenido.

[9] Por no haberse adoptado antes de ahora este sistema han quedado sin efecto las mejores instituciones y se han causado gastos infructuosos al Erario. En todos los ramos de la Administración pública debe de haber plan, orden, método y economía, y deben estar marcadas de un modo claro y preciso las funciones respectivas a cada uno. Lo contrario produce confusión, desorden y falta de armonía en las providencias que se toman por todos y cada uno de ellos, sucediendo muchas veces que los Jefes en la Corte y las provincias se hallan a un tiempo mismo con decretos y órdenes a las cuales no pueden dar cumplimiento por temor, y aun seguridad, de que sus disposiciones producirán efectos contrarios. Son infinitos los ejemplares que pudiera citar en apoyo de esta verdad que no necesita testimonios, porque son demasiadamente conocidos entre nosotros. De aquí la necesidad de ponerlos fin, como es de esperar

tante hace el mayor honor a los sujetos de dentro y fuera de las Cortes a quienes se cometió el desempeño de este delicado trabajo. Por consiguiente, tenemos dados pasos muy agigantados hacia el bien por que tanto anhelamos; y es de esperar que a beneficio de buenas instituciones lograremos al fin vencer al tirano y consolidar la prosperidad futura del hermoso y desgraciado suelo español en el que afortunadamente hemos nacido.

(2) La educación tiene sin duda alguna un influjo notable en las operaciones del hombre y en los ulteriores progresos del entendimiento humano. Sin cultivar este no pueden concebirse sino ideas vagas y equivocadas, aún de la Divinidad. ¿Cuál sería el estado actual de mejora y perfección de las artes y la ciencia si hubiese faltado el modo de aprenderlas por principios? Es preciso confesar que subsistirían aun en la infancia. ¿Qué sería de los hombres si habiéndose multiplicado su especie en número prodigioso no hubieran muchos de ellos descubierto, adelantado y perfeccionado los medios de subsistir sobre la tierra y no se hubiesen procurado por medio de su trabajo y aplicación el modo de atender a su subsistencia, aseo y regalo? Pertenecerían necesariamente a la clase de los selvages (sic) o de los restantes hombres que por falta de civilización habitan en los montes como las fieras, sin más habitación que las cuevas que la naturaleza ha formado en ellos, sin otro alimento y regalo que las frutas que espontáneamente producen los árboles silvestres, y sin otro aseo y abrigo que el que les facilita el uso de las pieles de los animales feroces y las hojas de los arbustos de que abundan los bosques que les sirven de recreo y de guarida. ¿Y cuáles serían las relaciones que podrían establecer esta carta de seres? Entiendo que ninguna; luego no podrían entablar comunicaciones entre sí ni con los demás hombres civilizados; y por consiguiente ni aún estarían en estado de conocer sus necesidades respectivas ni el modo de subvenir a ellas. Un Gobierno sabio debe promover una educación ilustrada, la cual entre otras ventajas producirá la destrucción de las antiguas injustas preocupaciones que han hecho mirar hasta ahora con desprecio las clases industriosas y productivas, a las cuales no se han premiado ni distinguido como merecen por sus recomendables trabajos y útiles descubrimientos, olvidándose que el producto de las fatigas de estos beneméritos ciudadanos son los que constituyen la verdadera riqueza y fuerza de un Estado y hacen la prosperidad nacional, sin la cual no pueden mantenerse ejércitos, no puede sostenerse y aumentarse la Marina, ni es posible conservar las Colonias; y lejos de que reine la abundancia y haya particulares acomodados que contribuyan a sostener la dignidad de la Soberanía habrá únicamente vasallos pobres y desvalidos con los que solo se podrá presentar un cuadro bien desagradable y desaliñado. 
se ejecute en vista de que el soberano Congreso tiene decretada la división de los poderes legislativo, ejecutivo y judiciario. Esta medida saludable exige forzosamente otra, cual es la clasificación de los Ministerios y Secretarías del Despacho, órganos por donde se comunican las disposiciones superiores a los Jefes de todos los ramos de la Administración pública, a los de la Fuerza Armada y a los ejecutores de las leyes, ya sea en los términos que propuso el Excmo. Sr. D. Eusebio de Bardají y Azara en su proyecto de 28 de septiembre de 1810, o en otros que se juzgasen más adecuados, siempre que reúnan las cualidades necesarias a hacerlo practicable.

[10] A mi entender, el que dejo citado lo hallo bastante conforme a las ideas liberales que nos deben dirigir en el nuevo orden de cosas, especialmente el segundo de los ocho que cree oportuno se sancionen con el título de Gobernación General del Reino ${ }^{(3)}$, por ser el que tiene relación con los grandes objetos de que trato en este pequeño discurso, y porque en la mayor parte son los mismos que debía desempeñar el Departamento del Fomento General del Reino establecido en 1802 a impulsos del actual ilustrado Sr. Ministro interino de Hacienda de España.

[11] Parecerá a muchos inútil la erección de un nuevo Ministerio existiendo ya un establecimiento que en época más feliz que la presente podrá volver a ejercer sus antiguas funciones; y no pocos lo considerarán gravoso al Erario, especialmente en su actual escasez de fondos. Voy a demostrar, 1, los inconvenientes, trabas y estorbos que se opusieron a que el Departamento citado pudiese desempeñar los objetos de su instituto, los mismos que subsistirán en todo tiempo no variando su forma y constitución; y 2, que en nada gravó al Erario su establecimiento y manutención, como no debe gravar tampoco al mismo el Ministerio de Gobernación, aplicándole los fondos que se señalaron a aquel para sostenerle.

[12] Muchos e interesantes fueron los trabajos en que ocupó el referido Departamento desde su erección en 1802 hasta la revolución en 1808, de los cuales algunos se imprimieron y publicaron, y otros sirvieron sólo de conocimiento al Gobierno, porque en el sistema antiguo había interés en ocultar todo lo que pudiera contribuir a descubrir el desorden y abandono del sistema de administración del Reino. Como la materia era demasiado nueva entre nosotros, hubo necesidad de vencer grandes dificultades antes de conseguir reunir las noticias y datos necesarios para formalizarlos, porque los encargados en las provincias y puertos habilitados del Reino de adquirirlas y uniformarlas con arreglo a los modelos que dispuso el Departamento al efecto hallaron en los Ayuntamientos y particulares la oposición consiguiente a los temores y sobresaltos que les causaba toda indagación por parte del Gobierno sobre la riqueza territorial, los productos de la industria y la entidad de su respectivo comercio y tráfico; y no debe parecer extraordinario sucediese así, cuando las más veces tenían por objeto real estas averiguaciones el de imponer un nuevo tributo o recargar los ya establecidos, dimanando de todo o que no se prestaban a dar las razones que se les pedían ni auxiliar a los encargados de recogerlas, o cuando las facilitaban eran muy diminutas e inexactas, habiéndose visto obligado por esta razón el Gobierno para llevar a cabo la formación de la estadística de Avila, única que se redactó, a enviar a esta capital al Oficial $4^{\circ}$, para que recorriéndola personalmente pudiese rectificar sobre el terreno las noticias y datos que se le habían suministrado de aquella provincia, en cuya comisión empleó dos años. A fuerza, pues, de tesón y de explicaciones

(3) En la mañana del 18 de agosto último se leyó en las Cortes el plan de Constitución para la Monarquía española en cuanto tiene relación con los poderes legislativo y ejecutivo; en el artículo de Ministerios se señalan los que deben establecerse, y el de la Gobernación es el segundo de los ocho que se designan. 
sobre las verdaderas ideas que el Rey se proponía conseguir al exigir razones semejantes ${ }^{(4)} \mathrm{se}$ lograron concluir algunos trabajos de los que le estaban encargados, los cuales hubieran podido servir en el día con fruto a haberlos podido sustraer de Madrid para ilustrar muchas de la materias que se cuestionan en el actual Congreso nacional, y de que por desgracia nuestra hay entre nosotros ideas muy confusas e inexactas. Sus progresos hubieran podido ser muy rápidos si a los pocos meses de establecida y hecha la paz con Francia no nos hubiéramos empeñado en la guerra marítima con la Inglaterra, la cual interrumpió nuestras comunicaciones y tráfico mercantil por mar con el Extranjero y con las posesiones españolas en América; y si el Gobierno hubiera continuado dispensando al Departamento la consideración y protección con que lo distinguió a los principios de su erección, y era necesaria para hacer obedecer las órdenes que por él se comunicaban a los Jefes en las provincias y pueblos habilitados para el comercio exterior y de ultramar para la adquisición de los datos y noticias sobre que había de fundar sus observaciones y cálculos. A esta falta de apoyo y protección dieron motivo ciertos pueriles resentimientos suscitados contra los promovedores de este establecimiento y personas elegidas para componerlo por otras que recelaron perder con el tiempo una parte de su consideración, facultades, prerrogativas o influjo en los negocios que habían manejado y deseaban conservar, y por temor de que pudieran sustraerse otros de su conocimiento si lograba el Departamento acreditarse por medio de sus útiles tareas y trabajos; y como en esta clase de luchas vence siempre el que tiene a su disposición la fuerza o los medios de usarla, invocando la razón y la justicia, el Departamento tuvo que sucumbir a los esfuerzos de sus contrarios, tanto más reprehensibles cuanto que por satisfacer su encono sacrificaban los intereses del Rey y los del Estado.

[13] Todas estas trabas desaparecerían con la erección del Ministerio de la Gobernación General del Reino, cuyas principales atribuciones son las marcadas al Departamento del Fomento y Balanza de Comercio, que debe refundirse en él, aunque con extensión a otros objetos que este no abrazaba, pero que por su íntima conexión y enlace deben caminar unidos, porque

(4) Por útil y ventajoso que sea a la causa pública un establecimiento nuevo, halla siempre en el desempeño de los encargos que se le confían trabas, obstáculos y dificultades que vencer, especialmente si choca con los intereses de Cuerpos colegiados o de particulares a quienes puede perjudicar la corrección de los abusos y desórdenes introducidos en su manejo o administración; y está en el orden que no perdonen medio, fatiga ni dispendio que pueda ser capaz de hacer ilusorias las providencias que se dicten a conseguir aquellos saludables fines o pueda contribuir a desacreditar y destruir las esperanzas que se concibieron de él al crearlo. No pocas veces se logra el intento, y la experiencia tiene bien acreditado haber habido muchos de esta especie que se han malogrado o por la ignorancia de los que se han colocado al frente de ellos, o por los esfuerzos de los interesados en su ruina, viniendo a verificarse aquel axioma constante de que en España todo se emprende y nada se concluye. Y si los Cuerpos y particulares suelen muy frecuentemente lograr estas ideas destructoras del bien y felicidad general, ¿qué deberá recelarse cuando se mezclan los intereses de las naciones extrañas por los perjuicios que pueden producir a su privativa agricultura, industria y erario las medidas que otra tome para procurar el adelantamiento y estabilidad en su suelo de estos ramos de felicidad pública? Por lo tanto, al paso que todo Gobierno sabio debe manejarse con pulso, delicadeza y tesón en todo lo que tenga relación a este último caso, debe cuidar de proceder en las medidas que tome dentro de los límites de su jurisdicción para la adquisición de datos y noticias relativas a la agricultura, industria y tráfico interior con la franqueza, buena fe y verdad necesarias a adquirir confianza pública; y si posible fuese, hacer ver con pruebas claras y terminantes la pureza de sus intenciones. En el antiguo régimen era muy difícil conseguir este fin porque casi siempre estaban en contradicción las palabras con las obras. 
no dependiendo este nuevo Ministerio de otro superior a él, no habrá el inconveniente que tocó el Departamento del Fomento, es decir, no hallará quien entorpezca la marcha de sus providencias, ni se oponga al cumplimiento de las órdenes soberanas que por él se comuniquen. De otro modo, no será posible vencer este escollo, que es el que en esta parte, subsistiendo el antiguo régimen y confusión en los negocios, se opondría siempre a los saludables fines del Gobierno.

[14] Las funciones del referido nuevo Ministerio están detalladas en el proyecto citado, y el modo más atinado de dar idea de ellas en este lugar entiendo será el de copiar a la letra su contenido. Dice así:

A este Ministerio debe pertenecer cuanto es relativo a la Administración civil del Reino y la policía municipal de todos los pueblos sin distinción; la policía del Reino tomada en sus dos acepciones capitales, esto es, la salubridad y buen orden en los abastecimientos y mercados, la limpieza de las poblaciones y su embellecimiento, la seguridad pública en los pueblos y ciudades y en los caminos, el orden y dirección en los teatros y demás diversiones públicas, y todo lo que es relativo al aseo, decencia, seguridad, orden y sosiego interior del Estado; y por otra parte, el cuidado en descubrir las tramas de los mal intencionados y de observar y comprimir convenientemente todo manejo, conventículo o inconsiderada propalación que se dirija a perturbar el sosiego interior o la seguridad pública; debiendo por consiguiente ser del resorte de la policía el examen de la conducta de las gentes sin ocupación, mal entretenidas o sospechosas ${ }^{(5)}$. Pertenecerá también a este Ministerio todo lo relativo a la instrucción o enseñanza pública, como colegios, universidades, academias, escuelas elementales y establecimientos de ciencias y artes, con cuanto pertenezca a estos interesantes ramos de la ilustración nacional. Asimismo le pertenecerán los caminos, canales, acequias, disecación de lagunas o pantanos y toda obra pública rural o de entretenimiento u ornato, y la sanidad. Serán de su resorte las fábricas y demás ramos de instrucción nacional, en aquella parte que el Gobierno deba tomar en su fomento y prosperidad $^{(6)}$; como también cuanto tenga relación con los adelantamientos de la agricultura y los establecimientos públicos de ella; las minas y canteras; casas de monta; cría de ganados, y la navegación y comercio interior $^{(7)}$; no menos que los hospitales civiles, lazaretos, casas y establecimientos de misericordia y beneficencia. Se despacharán por este Ministerio los asuntos de las encomiendas de los señores Infantes, la Imprenta Real y, en una palabra, cuanto tenga relación con la fijación de límites de

(5) Esta parte de la policía no debería en ningún concepto separarse del conocimiento y dirección del Ministerio de Gracia y Justicia, por ser el que mantiene por otros respectos una no interrumpida correspondencia con los Tribunales superiores y territoriales, quedando solo al cargo del de la Gobernación lo relativo al aseo, orden y ornato.

(6) El Gobierno debe declararse protector de todo establecimiento industrial de cualquiera clase que sea, contribuyendo a su fomento y prosperidad por los diferentes medios que dependen de su autoridad y facultades; pero no le es conveniente sostenerlos de su cuenta y riesgo, y la experiencia puede haberle desengañado ya de cuán infructuosas sumas ha expendido antes de ahora en objetos de esa naturaleza.

(7) Por la lectura del proyecto se descubre que el Ministerio de Hacienda debe continuar conociendo de todo lo relativo al comercio y navegación de la Península y (sic) a puertos extranjeros, debiéndose formar consiguientemente por él la balanza de nuestro comercio con las naciones extrañas. Si este trabajo ha de continuarse formando por las relaciones de entradas y salidas que facilitan las Aduanas habilitadas del Reino, es claro que este Ministerio a quien están sujetas deben ocuparse en él, manteniendo con el Ministro de Estado una no interrumpida correspondencia, por ser el que se entiende con los empleados y agentes diplomáticos en las Cortes y puertos extranjeros de quienes es preciso exigir noticias y datos político-mercantiles para ilustrar y perfeccionar esta obra. No pienso del mismo modo mismo modo con respecto al comercio y navegación de cabotaje, cuyos ramos no separaría del Ministerio de la Gobernación por el enlace que tiene con los demás que se le designan. 
las provincias o pueblos y a su estadística ${ }^{(8)}$ y economía política en general; como también todos los negocios que corran ahora por otros Ministerios y que se consideren deben pertenecer al interior del Reino $^{(9)}$.

[15] No hay objeto de cuantos quedan indicados que no sean dignos de la más alta atención. No puede haber hombre alguno de luces y conocimientos que pueda dejar de confesar que todos ellos bien manejados, fomentados y protegidos son capaces de hacer la felicidad de un Estado. La Comisión de Cortes encargada de examinar este proyecto presentado por el señor Ministro de Estado al Consejo Supremo de Regencia, y apoyado por este en todas sus partes, dice sabiamente en su informe "que la ejecución del nuevo arreglo de Ministerios es, en general, de una evidente utilidad, y aun de conocida necesidad. Se trata de separar de cada Ministerio el despacho de una multitud de negocios que no deben ser de su conocimiento o competencia, si se consideran las verdaderas atribuciones que han de pertenecer a cada uno para que haya orden, sistema y celeridad en la Administración. La manía, añade, de manejar muchos negocios, el flujo de tener muchas dependencias, y por consiguiente de hallarse en el caso de hacer más gracias y de dar más empleos ${ }^{(10)}$; y, por fin el errado concepto de que los

${ }^{(8)}$ Las estadísticas particulares a las provincias del Reino deben formarse en ellas con arreglo a lo dispuesto en el último Reglamento de las Juntas Provinciales, eligiendo para este trabajo sujetos de luces, instrucción y conocimientos en los diversos ramos que deben abrazar, de que no se carece en la mayor parte de ellas si se saben interesar con premios y recompensas correspondientes a sus fatigas, sin gravamen del Erario. En el propio Reglamento se encarga a las Juntas dirijan a la Superioridad estos trabajos luego que se verifique su conclusión, para su conocimiento; con lo cual, y la reunión de todos los de su especie de las demás provincias en el Ministerio de que trato, se logrará formar una estadística general del Reino, la cual a un golpe de vista presentaría el grandioso cuadro de la riqueza territorial, industrial y comercial de la Monarquía española; resultando de las observaciones y notas con que se instruya las mejoras, adelantamientos y perfección de que podrán ser susceptibles todos y cada uno de los ramos que la constituyan y forman las bases de la felicidad general de los pueblos y la de sus habitantes, cuya riqueza es precursora de la del Estado a que pertenecen y contribuyen no solo a mantener su dignidad, integridad e independencia, sino también a sostener al Jefe que la dirige o gobierna con el correspondiente brillo, ornato y pompa. En Francia se forman las estadísticas de los Departamentos en que está dividido aquel Imperio por los Prefectos y Sub-prefectos, empleos equivalentes a nuestros Intendentes de Provincia; pero aquella Nación es más antigua que la nuestra en el conocimiento de la importancia de estas investigaciones. Lo son también la Inglaterra y la Alemania; y aún la Rusia ha presentado algunos trabajos de esta especie, dándonos idea en sus papeles públicos de que está ya al alcance de saberlos apreciar y conocer sus utilidades.

(9) Observo que nada se trata en el proyecto que tenga relación con los censos o estados de población, objeto que merece toda consideración por su importancia y consecuencias. A mí me parece que este trabajo corresponde desempeñarse por el Ministerio de la Gobernación, renovándolo al menos de cinco en cinco años. Por ese medio se sabrá aproximadamente el aumento o decadencia que experimente, y podrá entrarse con seguridad en el examen de las causas que influyan en cualquiera de los dos extremos.

${ }^{(10)}$ Esta es una proposición de eterna verdad que no necesita pruebas; y una triste experiencia nos ha hecho ver que este debe ser uno de los principales motivos que induzcan a una resistencia tenaz en los casos en que se intente segregar de alguno de los Ministerios negocios que esté en posesión de despachar. Uno de los señores Ministros manifestó en su informe sobre el proyecto de que se trata que de adoptarlo se causaría un ejemplar que no había habido hasta aquí, e iría contra la práctica y método ya establecido con buen éxito. La Comisión de Cortes observa juiciosamente que el haberse observado una cosa hasta ahora no es suficiente razón para que siga observándose en adelante, y que si todo negocio a que pudiese atribuirse Gracia o Justicia hubiese de pertenecer por ello a este Ministerio, no 
grandes negocios de la Administración pública quedan despachados con la expedición de una multitud de detalles que cuando más son de un resorte muy secundario. Todas estas causas, y otras nacidas del acaso, de la preponderancia o del influjo de este o aquel Ministro en el antiguo tiempo, han dado en gran parte origen al vicioso estado de repartimiento de negociados que la Regencia desea enmendar, y que la Comisión cree deber tener una pronta enmienda. Mientras no se haga esta separación de un modo más análogo a las verdaderas atribuciones de cada Ministerio, los Ministros, embarazados con negocios que les son extraños y abrumados con la molesta carga de mil detalles inconexos, no podrán dedicarse a lo que verdaderamente debe ocupar toda su atención, a saber, planes y medidas en grande, reformas útiles y bien calculadas, y vigilancia de cada momento sobre la mejor ejecución de las leyes y el mantenimiento del orden y felicidad general. Por lo tanto, la Comisión gradúa de feliz este pensamiento, y lo tiene por único para dar a la Administración general e interior del Reino la unidad de acción y de miras que debe proponerse todo Gobierno que aspire a la felicidad de la Nación que dirija".

[16] Concluiré expresando que el establecimiento de este Ministerio no causa perjuicio ni recargo alguno a los fondos del Erario; y me atrevo a asegurar que en el caso de que los causara, al parecer por que sus gastos hubiesen de cubrirse con parte de los rendimientos de las rentas del Estado, probaría hasta la evidencia que su costo no guardaría proporción con las ventajas y mayores utilidades e importancia de los beneficios que recibirían la agricultura, industria, artes, comercio, navegación, pesca y demás de utilidad general, y las mayores sumas que por efecto del fomento y extensión de estos ramos y su mayor tráfico y circulación entrarían en el Tesoro público; pero no nos hallamos en este caso, pues que para atender al pago de los sueldos, gastos de escritorio y demás que ocasionaba el antiguo Departamento del Fomento estaban señalados fondos y arbitrios que aplicados al Ministerio de la Gobernación General del Reino serán más que suficientes a cubrir sus más principales obligaciones. Estos arbitrios consisten en ciertos derechos que se cobran en el embarco y desembarco de varios artículos de nuestro comercio que cobran los Consulados de España y América, habiendo declarado que los caudales que procedentes de estos arbitrios se remitan a la Península desde las posesiones ultramarinas con destino al Departamento sean libres de todo derecho. Sus productos son cuantiosos en tiempo de paz, y la Tesorería General que los recaudaba y recauda contaba con un sobrante anual de bastante consideración. En Francia hay establecido un derecho con el título de Balanza de Comercio, que se cobra a la introducción y extracción de ciertos artículos que constan de un arancel particular al que están sujetos muchos efectos, aún de los no gravados con contribución alguna; su producto está destinado al pago de los sueldos y gastos que causa la oficina que cuida de formar los estados de su comercio con las

sería difícil probar que no debería de haber en el Reino sino uno solo con esta denominación; y yo añado que si porque un sistema observado hasta la época presente estuviese autorizado por las leyes y la práctica no pudiese ni debiese hacerse en él novedad, aún cuando de esa variación resultasen ventajas a la Nación, sería inútil y de ningún efecto la convocación y reunión de las Cortes, que tienen por objeto, entre otros, reformar, modificar, ampliar o establecer de nuevo unas instituciones acomodadas a las circunstancias actuales. Grandes progresos podríamos prometeros conseguir en las artes y las ciencias si adoptando este principio nos negásemos al estudio y meditación que exigen las mejoras y adelantamientos que son susceptibles, y a intentar por medio de ensayos y pruebas repetidas encontrar el modo de perfeccionarlas. 
naciones extrañas. En Inglaterra hay otro establecimiento que cuida de este y otros objetos de conocida importancia; y esta Potencia debe a sus esfuerzos, laboriosidad y conato por fomentar su industria, fábricas y comercio, y a su famosa Acta de Navegación, la riqueza y prosperidad de que goza, el poder que ostenta y su influjo actual en la balanza política.

[17] La materia sobre que versa esta Memoria es susceptible de tratarse con mayor extensión y peso; pero me persuado que basta lo dicho para que cualquiera de los que la lean queden convencidos de que no todos los establecimientos que se proyectan crear son inútiles y gravosos al Estado, y que no deja de haber algunos que en importancia, necesidad y ventajas son de tal tamaño que exceden en mucho al gasto o dispendio que puede originar el sostenerlos. De todos modos, conviene mucho examinarlos detenidamente antes de desecharlos; y para ello es indispensable entrar en pormenores que no están al alcance de una gran parte de los hombres, ni se ofrecen a su consideración en las primeras impresiones que causa un proyecto, especialmente si, como es regular, encierra ideas nuevas capaces por este solo respecto de granjearse el odio y desaprobación de los hombres poco reflexivos. El de que se trata es uno de los exceptuados de la regla general, tanto por su importancia cuanto porque teniendo fondos propios de que disponer no es una carga del Estado, a quien reporta incalculables beneficios.

[18] El Consejo Supremo de Regencia en su informe sobre el proyecto de que se trata, y la Comisión de Cortes en el suyo, lo han reconocido así, expresando que deben ocupar las plazas de la Secretaría del Ministerio de Gobernación General del Reino que se propone crear, así los Oficiales que de las demás Secretarías queden sobrantes por la reducción de sus respectivos negociados como los que componían en Madrid el Departamento del Fomento que han seguido al Gobierno legítimo y se hallan en partes libres de enemigos, en quienes deben suponerse conocimientos poco comunes en los asuntos que han de versarse en ella, así por sus principios cuanto por haberlos manejado algunos años por elección del Gobierno.

[19] Quedan manifestadas mis ideas en la materia de que trata este papel, las cuales podrá desenvolver otro con mayor acierto y tino para ilustrarla hasta el grado de que es capaz y conviene al interés general del Estado.

Cádiz, 20 de octubre de 1811

José Señán y Velázquez (rúbricado) 